\title{
Comparison of Quantification Methods for the Condensed Tannin Content of Extracts of Pinus Pinaster Bark
}

\author{
LINA PEPINO ${ }^{\prime}$, PAULO BRITO ${ }^{\prime}$, FERNANDO CALDEIRA JORGE ${ }^{2}$, RUI \\ PEREIRA DA COSTA ${ }^{2}$, M. HELENA GIL ${ }^{1}$ and ANTÓNIO PORTUGAL ${ }^{1}$ \\ 'Departamento de Engenharia Química da Faculdade de Ciências e Tecnologia da \\ Universidade de Coimbra, Pólo II-Pinhal de Marrocos, 3030 Coimbra-Portugal, ${ }^{2}$ Bresfor, \\ Indústria do Formol, S.A., Apartado 13,3830 Gafanha da Nazaré - Portugal
}

Abstract: Bark from Pinus Pinaster is an interesting source of polyphenolic natural compounds, that can be used successfully as total or partial replacement of conventional phenolic resins. These compounds, among other applications, are used as adhesives in the wood agglomerate industry. In this kind of application some problems remain to be solved in order to obtain a Pine extract of commercial value. It is necessary to optimise the extraction procedure and select a suitable method for the quantification of the tannin content of the bark. In order to study these problems, the tannin extraction from the Pine bark was tested with an alkaline solution $(\mathrm{NaOH})$, and with a fractionation procedure based on a sequence of an organic (ethanol) and aqueous extraction. The phenolic content of each extract or fraction was evaluated by the FolinCiocalteu colorimetric assay for total phenols and two procedures using the Stiasny reaction: the gravimetric Stiasny method and the indirect colorimetric procedure that uses the Folin-Ciocalteu reagent to evaluate the total phenols present in the extract solution before and after it condenses with formaldehyde. The yield value when the alkaline extraction is used is substantially higher than the values obtained with organic or aqueous solutions. However, the selectivity of the process is low. In fact, it was found that the alkaline extract Formaldehyde Condensable Phenolic Material (FCPM) content represents 95$96 \%$ of the total phenols content of the extract but this fraction is only $\approx 40 \%$ of the total mass of extract. So, the alkaline extract is relatively poor in phenolic material, exhibiting a large variety of non-phenolic extractives. On the other end, ethanol provides a very rich phenolic extract, in which $96 \%$ of total phenols are condensable with formaldehyde, but exhibits a relatively low extraction yield. The aqueous extract presents the lowest extraction yield with low content either in phenolic material as in FCPM, but, as most of the 
phenolics had already been extracted by the previous organic extraction, especially the low molecular weight fractions, this result was predictable.

\section{INTRODUCTION}

In recent years, since the OPEC petroleum crisis in the early $70^{\prime} \mathrm{s}$, there has been an increasing interest on research for natural and cheap alternatives to synthetic phenolic petroleum-based adhesives for wood industry. Condensed tannins from wood barks that are widely used in the tanning industry, proved to be a viable phenolic source for these applications ${ }^{6,7}$. Tannins are natural polyphenols, usually classified as ${ }^{2,6}:$ Hydrolyzable and Condensed Tannins or Proanthocyanidins. These groups involve structurally different chemical compounds. Their ability to bind and precipitate proteins is their main characteristic ${ }^{2,9}$. They are also able to condense with formaldehyde or undergo self-condensation without the need of any external reticulation agent. That characteristic confers adhesion properties to tannins ${ }^{3,7}$. Condensed tannins are complex polymers or oligomers of flavanoid units, namely flavan-3-ols and flavan-3,4-diols ${ }^{6}$, that can be found in significant quantities in the bark of several species of trees, namely of the Pinus genre. Pinus pinaster is the most abundant forest specie in Portugal, and its bark is especially rich in condensed tannins (procyanidins and to a lesser extent prodelphinidins). Therefore, Pinus pinaster bark is an eligible source of polyphenolic natural compounds, that can be used as replacement of conventional phenolic resins (phenol-formaldehyde, urea-formaldehyde or melamine-formaldehyde) for the wood agglomerate industry. In order to obtain useful extracts, the following problems have to be addressed ${ }^{6}$ : high reactivity of phloroglucinolic polymers (making the control of the polymerisation reaction difficult), high viscosities and low solubilities of the extract solutions (at least $40 \%$ of solid contents). As a first approach, it is necessary to optimise the extraction procedure and select a suitable method for the quantification of the tannin content of the bark. In this paper, the results obtained for the tannin extraction from the Pine bark with an alkaline solution $(\mathrm{NaOH})$ are presented. A fractionated extraction procedure was tested for tannin extraction of bark, using diethyl ether (for the elimination of lipophilic compounds) and a sequence of solvents with increasing polarity and decreasing specificity for tannins; ethanol and hot water ${ }^{5}$. The phenolic content of each extract or fraction was evaluated by the Folin-Ciocalteu colorimetric assay for total phenols ${ }^{11}$ and two procedures using the Stiasny reaction for the quantification of the Stiasny phenols (phenols that condense with formaldehyde): ( the traditional gravimetric Stiasny method ${ }^{12}$, 2 the indirect colorimetric procedure using the Folin-Ciocalteu reagent to evaluate the total phenols present in the extract before and after the precipitation reaction with formaldehyde ${ }^{10}$. The results obtained in each extraction reaction wields and phenolic content of the extracts, procedure in terms of extraction suitable solvent and quantification were comp

method

\section{MATERIALS AND METHODS}

\section{$2.1 \quad$ Reagents}

Gallic aeid catechin and Folin-Ciocalteu reagent were supplied by Sigma Chemical Co. Formaldehyde was graciously supplied by BRESFORIndústria do Formol, S.A.

\subsection{Sample Preparation}

Bark from 30 to 40 years old trees (Pinus pinaster) from the central region of Portugal was used. It was dried for 24 hours in an oven, with hot . $100^{\circ} \mathrm{C}$. Dried bark was grinded by means of a hammer mill to less than $1 \mathrm{~mm}$ diameter particles.

\subsection{Extraction Methods}

Two procedures (Fig 1) for tannin extraction from the bark were used: Two procedures (Fig 1) for tannin extraction from $\mathrm{NaOH}, 1 \%(\mathrm{w} / \mathrm{w})$; fractionated alkaline extraction with a solution of $\mathrm{NaOH}, 1 \%(\mathrm{w} / \mathrm{w})$, fractionated extraction using a sequence of solvents decreasing specipophilic components.

Alkaline Extraction. Tannins were extracted from samples $(200 \mathrm{~g})$ with $1000 \mathrm{ml} \mathrm{NaOH}, 1 \%(\mathrm{w} / \mathrm{w})$ (bark/solvent relation - 1:5) in a mechanically stirred reactor for $30 \mathrm{~min}$ at $90^{\circ} \mathrm{C}$. The suspension was separated by

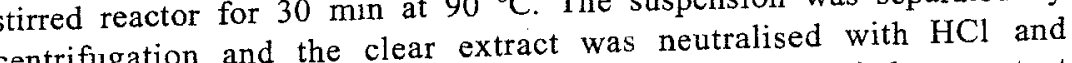
centrifugation and the clear extracted bark was dried to constant conditioned in recipients at $4{ }^{\circ} \mathrm{C}$. The extracted bark was dried to constant weight at $100^{\circ} \mathrm{C}$

Fractionated Extraction: For the sequential extraction (Fig 1) a Soxhlet as of we solvent sequence was used. Diethyl ether The extraction time for each procedure was defined by at least 50 (he boiling point of each solvent. The values cycles and the temperature was the boiling point of each solvent. The vaction were: 56 cycles (at $36^{\circ} \mathrm{C}$ ), 52 (at $78^{\circ} \mathrm{C}$ ) and 52 (at 98
used for the extraction 
$\left.{ }^{\circ} \mathrm{C}\right)$ for each solvent, respectively. The extracts were dried by vacuum distillation. The extraction yields are defined as:

$$
\eta=\frac{w_{d r . e x t}}{w_{b a r k}} \cdot 100
$$

where:

$\eta$ - yield of the extraction;

$w_{d r \text { ext }}$ - weight of the dried extract;

$w_{\text {bark }}$ - initial weight of the bark in each extraction procedure.

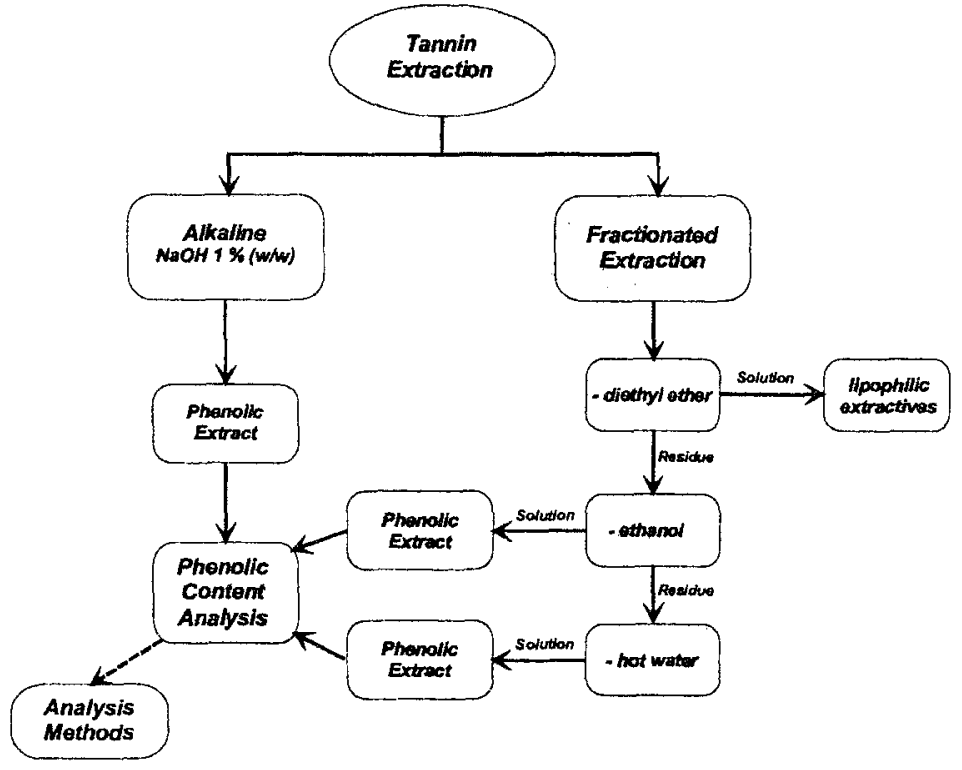

Figure 1. Scheme of the extraction procedures.

\subsection{Methocis of Analysis}

\subsubsection{Total Phenols:}

Total phenols were determined by the Folin-Ciocalteu colorimetric method" $^{\prime \prime}$ (Fig 2). $2.5 \mathrm{ml}$ of Folin-Ciocalteu reagent (diluted 10 times) and 2 $\mathrm{ml}$ of aqueous solution of sodium carbonate $(75 \mathrm{~g} / \mathrm{l})$ were added to $0.5 \mathrm{ml}$ of diluted extract, keeping the mixture $5 \mathrm{~min}$ at $50^{\circ} \mathrm{C}$. After cooling, absorbance was measured at $760 \mathrm{~nm}$ in a Jasco $7800 \mathrm{UV} / \mathrm{VIS}$ spectrophotometer. Aqueous solutions of catechin and gallic acid (8-40 $\mu \mathrm{g} / \mathrm{ml}$ ) were used as standards.

Calibration Curves Construction: calibration curves were constructed for both catechin and gallic acid using solutions of $8,16,24,32$ and $40 \mu \mathrm{g} / \mathrm{ml}$ and applying the procedure above described for the extract samples. Three replicates for each point were used.

\subsubsection{Stiasny Polyphenols:}

Stiasny polyphenols were determined by two different methods based on their ability to precipitate with formaldehyde (Fig 2):

Gravimetric Method ${ }^{12} .25 \mathrm{ml}$ of extract were acidified with $\mathrm{HCl}$ to $\mathrm{pH}=1$ and a molar excess of formaldehyde was added. This excess was calculated assuming that catechin and formaldehyde react in a 1:1 proportion. The suspension was refluxed during $30 \mathrm{~min}$. The reaction products were filtrated, washed several times with hot water and dried to constant weight at $100^{\circ} \mathrm{C}$. The polyphenol content is expressed in absolute terms by the "Stiasny precipitation number with formaldehyde", $\eta_{S t}$, defined by:

$$
\eta_{s t}=\frac{w_{p p}}{w_{i n i}} \cdot 100
$$

where:

$\eta_{s t}-$ Stiasny precipitation number;

$w_{p p}$ - weight of precipitate that reacted with formaldehyde;

$w_{i n i}-$ weight of initial extract.

The Stiasny number is useful as an absolute measure for the condensable polyphenols in the extract but does not represent itself the content of this phenolic material. Therefore, it can not be used directly as a quantification method for this type of materials. Additionally, it is a laborious, slow and messy procedure that demands large quantities of extract solution.

Colorimetric Indirect Method: based on the typical reaction of polyphenols with formaldehyde, Singleton ${ }^{10}$ proposed an assay for the quantification of phenolic material condensable with formaldehyde. He described a colorimetric procedure, instead of the gravimetric method, combining the Folin-Ciocalteu assay with the method of Stiasny (Fig 2). First, the total phenol content of the extract was measured before the precipitation reaction by the Folin-Ciocalteu method following the 
procedure described above. Then, $25 \mathrm{ml}$ of extract solution was acidified to $\mathrm{pH}=1$ and an excess of formalin $37.2 \%$ was added to the solution. The suspension was refluxed during $30 \mathrm{~min}$. The reaction products were removed by filtration and the total phenol content of the filtrate was measured again using the Folin-Ciocalteu method. The content of phenols that reacted was inferred by difference.

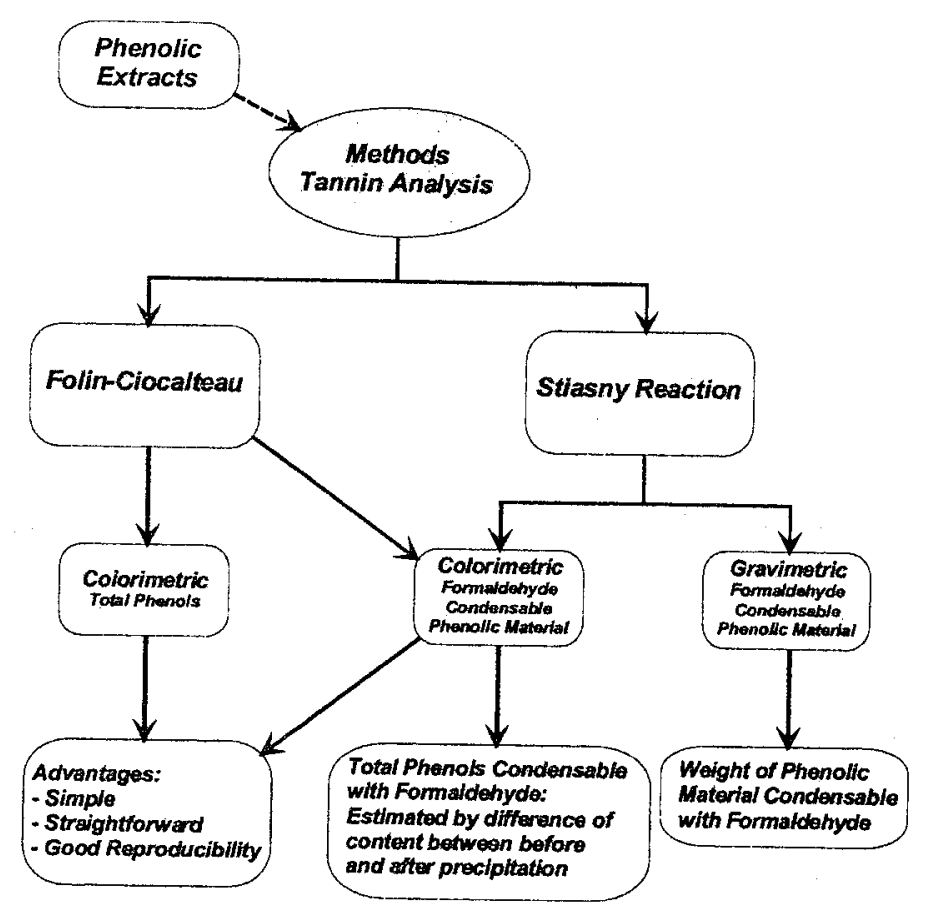

Figure 2. Methods used for the quantification of tannin content.

\section{RESULTS}

\subsection{Pine Bark Extraction}

The yields of each extraction procedure and its comparison with the values reported in the literature' are presented on Table 1.
Table 1. Yield obtained for each extraction.

\begin{tabular}{lll}
\hline \multicolumn{2}{l}{ Fractionated Extraction } & \\
\hline Solvent & Yield $(\%)$ & Yield from the literature $(\%)^{1}$ \\
\hline Diethyl ether & 6.7 & - \\
Ethanol & 8.9 & 10.3 \\
Water & 5.9 & 3.2 \\
\hline Alkaline Extraction & & \\
\hline NaOH $1 \%(\mathrm{w} / \mathrm{w})$ & 27.7 & - \\
\hline
\end{tabular}

The extraction yields obtained are of the same order of the ones available in the literature and it is noticeable that the yield for the alkaline extraction is substancially higher than the typical yields obtained by organic or aqueous extraction. However, it is predictable that the rougher conditions provided by the alkaline extraction would promote the extraction of considerable quantities of non-phenolic extractives which can negatively affect the adhesion properties of the extract. Therefore, the comparatively higher value for the extraction yield of the alkaline extraction can be explained by the lower specificity of the solvent to phenolics and the effective composition of the alkaline extract (which present a much greater variety of extractives) has to be carefully analysed and controlled to prevent the degradation of the properties of the extract.

\subsection{Quantification of Phenolics by the Method of Folin- Ciocalteu}

To quantify the phenolic material content of each extract by the method of Folin-Ciocalteu, a calibration curve absorbance-concentration is necessary. A known standard that could be considered to infer the concentration of the phenolic material, namely the oligomeric molecules of condensed tannins has to be selected. In this work, gallic acid and catechin, that can be considered the basic units for the most common molecules of hydrolyzable and condensed tannins, were used. Both standards usually provide good linear correlations, but catechin presents a lower colour intensity ${ }^{4}$. Therefore, gallic acid is the most used standard for these applications.

The calibration curves are presented in Figures 3 and 4. We can conclude that the relation absorbance vs. concentration can be acceptably fitted by a linear model for both standards. A slightly better correlation for the gallic acid was obtained (Fig 3). 


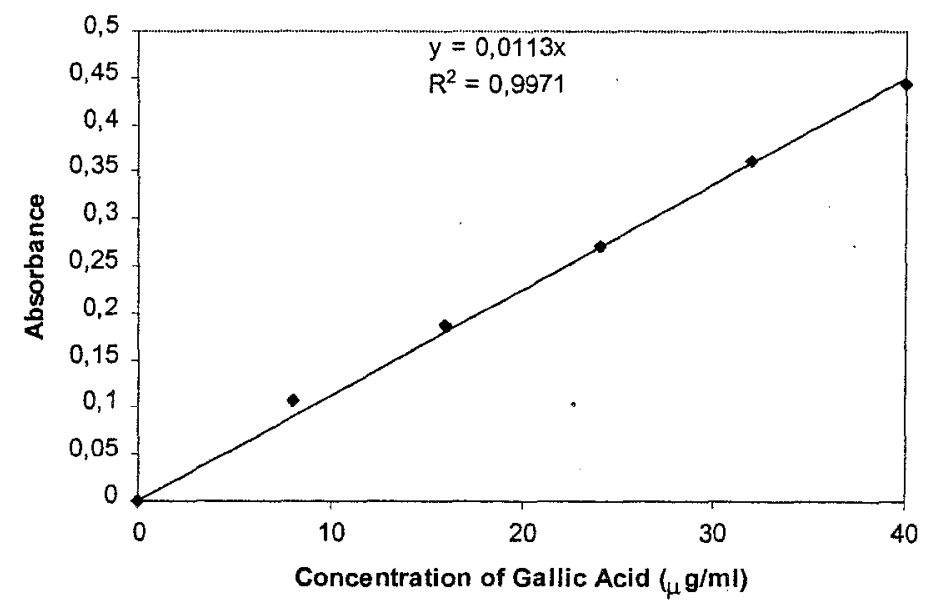

Figure 3. Calibration curve for the Gallic Acid.

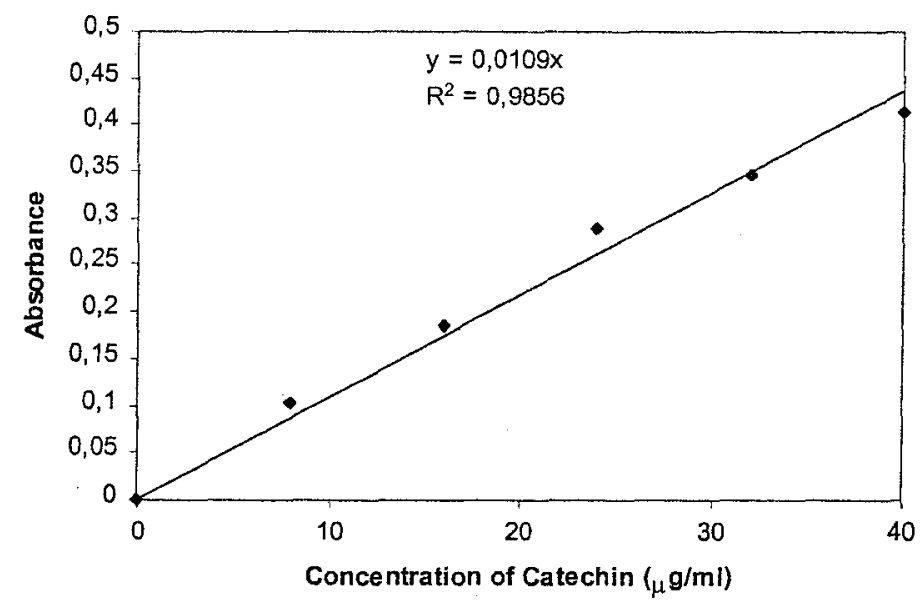

Figure 4. Calibration curve for the Catechin.

The results with gallic acid and catechin calibration curves are consistent (Table 2).
Table 2. Total phenols content in each extract by the Folin-Ciocalteu method.

\begin{tabular}{lll} 
& \multicolumn{3}{c}{ \% of total phenols in the extract } \\
\cline { 2 - 3 } & \multicolumn{2}{c}{ Catechin equivalents } \\
\hline Fractionated Extraction & & Gallic Acid equivalents \\
\hline Ethanol & 92.9 & 92.9 \\
Water & 12.6 & 11.6 \\
\hline Alkaline Extraction & & 41.2 \\
\hline NaOH $1 \%(w / w)$ & 42.3 & \\
\hline
\end{tabular}

By analysis of Table 2 we observed that the richest extract in phenolic materials is the ethanol extract, as we would expect. The aqueous extract presented the lowest value. That can be explained by the fact that most of the phenolics had already been extracted by the previous organic extraction, especially the low molecular weight fractions, more soluble in water. Another possible justification for this low value could be the quantification method used that, as every redox method, is affected by the variation of the hydroxylation base and by the degree of polymerisation of the phenols ${ }^{8}$. The alkaline extracts exhibit an intermediate value that enforces the idea that the alkaline treatment provides a reasonable quantity of phenolic extractives but also significant quantities of other types of compounds.

\subsection{Quantification of Phenolics Using the Stiasny Reaction}

Comparing the results obtained for the two Stiasny procedures adopted, we can conclude that the results obtained are consistent (Table 3 ).

\begin{tabular}{|c|c|c|c|c|c|}
\hline & \multicolumn{2}{|l|}{$\% \mathrm{FTFti}$} & \multicolumn{2}{|l|}{$\%$ FTm extr } & \multirow[b]{2}{*}{$\eta \mathrm{St}$} \\
\hline & $\begin{array}{l}\text { Catechin } \\
\text { equivalents }\end{array}$ & $\begin{array}{l}\text { Gallic Acid } \\
\text { equivalents }\end{array}$ & $\begin{array}{l}\text { Catechin } \\
\text { equivalents }\end{array}$ & $\begin{array}{l}\text { Gallic Acid } \\
\text { equivalents }\end{array}$ & \\
\hline \multicolumn{6}{|c|}{ Fractionated Extraction } \\
\hline Ethanol & 95.8 & 95.8 & 89.0 & 89.0 & 75.2 \\
\hline Water & 36.9 & 34.2 & 4.6 & 4 & - \\
\hline \multicolumn{6}{|c|}{ Alkaline Extraction } \\
\hline $\mathrm{NaOH} 1 \%$ & 96.1 & 95.1 & 40.6 & 39.6 & 57.3 \\
\hline
\end{tabular}

$\mathrm{FT}_{\mathrm{Fti}}$ - Percentage of formaldehyde condensable material related to total phenols content in the extract.

FT $_{\text {mextr }}$ - Percentage of formaldehyde condensable material related to total mass of initial extract.

$\eta_{\mathrm{St}}$ - Stiasny Number, defined by the relation between the mass of formaldehyde condensate and the mass of initial dry extract used in the reaction.

Considering the organic extraction, we verify that the Formaldehyde Condensed Phenolic Material (FCPM) content represents almost $96 \%$ of the 
initial total phenol content of the extract and $89 \%$ of the initial mass of the same extract. This result confirms the results presented in the above section. It is a clear indication of the abundance of phenolic material in the extract. Furthermore, it is noticeable that most of this phenolic material is condensable with formaldehyde. Therefore, the gravimetric Stiasny number is relatively high although not as high as we would expect.

The aqueous extract reveals low contents either in phenolic material as in FCPM. These values can be due to the fact that water dissolves preferentially low weight polyphenols. However, it is important to emphasise that this extract was concentrated in a rotating evaporator, where the removal of water was increasingly difficult as the extract became more concentrated and viscous. In the later stages of the operation the ebullition was violent making the polymerisation of the polyphenols possible, diminishing their reactivity to formaldehyde. Considering the very low value for the $\mathrm{FT}_{\text {mextr }}$ of the water, we can conclude that the aqueous extract contains a significant amount of non-phenolic compounds, typically simple sugars and polymeric carbohydrates $^{7}$. It was not possible to apply the gravimetric method to the aqueous extract since the polyphenols-formaldehyde complexes formed were soluble and could not be separated from the solution by filtration.

Finally, the alkaline extract FCPM content represents $95-96 \%$ of the total phenols content of the extract. However if this fraction is compared to the total mass of extract, we verify that this value is much lower: $\approx 40 \% ; \eta_{\mathrm{St}}$ $=57.3$, supporting the idea that the alkaline extract is relatively poor in phenolic material, presenting a number of non-phenolic extractives.

\section{CONCLUSION}

The yield for the alkaline extraction of tannins from Pinus pinaster bark, is substancially higher than the typical yields obtained by organic or aqueous extraction. However, the specificity of the solvent to phenolics is low. Enforcing that conclusion we observed that the alkaline extract FCPM content represents $95-96 \%$ of the total phenols content of the extract. However, when this fraction is compared to the total mass of extract, we verified that this value is much lower $\left(\approx 40 \% ; \eta_{\mathrm{St}}=57.3\right)$, which confirms the idea that the alkaline extract is relatively poor in phenolic material, presenting a variety of non-phenolic extractives. The most specific solvent is ethanol, that, in spite of revealing a relatively low extraction yield, provides a very rich phenolic extract, in which $96 \%$ of total phenols are condensable with formaldehyde. The aqueous extract presents the lowest extraction yield, with a low content either in phenolic material and FCPM. However, that can be due to the fact that most of the phenolics had already been extracted by the previous organic extraction, especially the low molecular weight fractions.

\section{REFERENCES}

1. Anonymus (undated); Desenvolvimento de Adesivos com Incorporação de Taninos da Casca do Pinheiro para a Produção de Aglomerados de Madeira, Relatório Final - Projecto PBIC/C/AGR/2331/95, JNICT.

2. Cannas, A., 1999; "TANNINS: Fascinating but Sometimes Dangerous Molecules", http://www.ansci.comell.edu/plants/toxicagents/tannin/index.html.

3. Jorge, F. C., Neto, C. P., Irle, M., Gil, H., Pedrosa de Jesus, J., 1998, Wood Adhesives Based on Self-Condensation of Pine Bark Tannins, Proc. 2nd European Panel Products Symposium, Llandudno, Wales, 21-22 Sept.

4. Julkunen-Tiitto, R., 1985, Phenolic constituents in the leaves of northern willows: methods for the analysis of certain phenolics, J. Agric. Food Chem., 33: 213-217.

5. Laks, P. E., 1991, "Chemistry of Bark", in Wood and Cellulosic Chemistry (Hon, D. N. S. and Shiraishi, N., eds.) Cap. 7, Marcel Dekker Inc., New York, pp 257-330.

6. Pizzi, A., 1983, "Tannin-Based Wood Adhesives", in Wood Adhesives: Chemistry and Technology (Pizzi A., ed.) Cap. 4, Marcel Dekker Inc., New York, p. 177-248.

7. Pizzi, A., 1994, "Tannin-Based Wood Adhesives", in Advanced Wood Adhesives Technology (Pizzi A., ed.) Cap. 5, Marcel Dekker Inc., New York, p. 149-217.

8. Price, M. L., Butler, L. G., 1977, "Rapid visual estimation and spectrophotometric determination of tannin content of sorghum grain", J. Agric. Food Chem., 25 (6): 12681273.

9. Ribéreau-Gayon, P., 1972, Plant Phenolics, Cap. 7, Oliver \& Boyd, Edinburgh, pp. 169197.

10. Singleton, V. L., 1974, Analytical fractionation of phenolic substances of grapes and wine and some practical uses of such analyses, American Chemical Society, Adv. Chem. Ser., Washington, D.C., 137: 184.

11. Singleton, V. L., Rossi Jr., J. A., 1965, Colorimetry of total phenolics with phosphomolybdic-phosphotungstic acid reagents, Am. J. Enol. Viticult., 16: 144-158.

12. Wissing, A., 1955, The Utilization of Bark II - Investigation of the Stiasny Reaction for the Precipitation of Polyphenols in Pine Bark Extractives, Svensk Papp., 58 (20): 745-750. 